\title{
The Preliminary Approach for the Human Cancer Regression by the Interaction between Human Bilateral Symmetrical Parts-Ou MC Decrescendo Phenomenon
}

\author{
Ming Cheh Ou ${ }^{1,2^{*}}$, Dennis Ou ${ }^{3}$, Chung Chu Pang4 \\ ${ }^{1}$ Department of Obstetrics and Gynecology, Taipei City Hospital, Taipei City, Taiwan \\ ${ }^{2}$ Department of Obstetrics and Gynecology, Taipei Medical University, Taipei City, Taiwan \\ ${ }^{3}$ Department of Mechanical Engineering and Biomedical Engineering, Carnegie Mellon University, \\ Pittsburgh, USA \\ ${ }^{4}$ Department of Obstetrics and Gynecology, Su Women Hospital, Taipei City, Taiwan \\ Email: mcou@ym.edu.tw
}

Received 20 January 2015; accepted 10 February 2015; published 11 February 2015

Copyright (C) 2015 by authors and Scientific Research Publishing Inc.

This work is licensed under the Creative Commons Attribution International License (CC BY).

http://creativecommons.org/licenses/by/4.0/

(c) (i) Open Access

\section{Abstract}

Ou MC decrescendo phenomenon (OuDP) is induced by interaction between human bilateral features and has shown to alleviate or cure infectious and non-infectious diseases. The resolution of non-infectious conditions with OuDP indicates to be consistent with restoration of normal tissue function (AJEM, 2012; Proc Physiol Soc, 2014). Ou MC handing remedy (HR) was utilized to induce OuDP by applying the hand to the contralateral body. Four female patients received self-administered HR separately for their diseases: 1) uterine endometrioid carcinoma stage IIIB, 2) suspicious pancreatic cancer in stage IA with isodense pancreatic nodule, elevated CA199 and dilated tortuous main pancreatic duct, 3) uterine leiomyosarcoma stage IB, and 4) suspicious gluteal metastatic lesion of chronic myelogenous leukemia. The treatments with HR showed to suppress or ameliorate oncologic changes for these patients: 1) The uterine endometrioid carcinoma regressed from stage IIIB to IA with $\mathbf{5}$ months treatment. 2) The pancreatic isodense lesion decreased from $1.6 \times 1.7$ to $1.0 \times 1.0 \mathrm{~cm}$ in size with CA199 descending from 1090.0 to $136.5($ Unit $/ \mathrm{ml})$ associating with the main pancreatic duct diameter decreasing from 0.39 to $0.14 \mathrm{~cm}$ with tortuosity disappearance after 4 months treatment. 3) The frequent profuse bleeding by uterine leiomyosarcoma prominently decreased immediately with $\mathrm{HR}$ and subsequent HR was also effective at minimizing heavy uterine bleeding in the 3 weeks treatment. 4) The gluteal macular lesion of the case with chronic myelogenous leukemia was eliminated with 2 weeks treatment. It reveals OuDP may normalize the tumor cells and microenvironment function, which makes tumor cells conform to the

\footnotetext{
${ }^{*}$ Corresponding author.

How to cite this paper: Ou, M.C., Ou, D. and Pang, C.C. (2015) The Preliminary Approach for the Human Cancer Regression by the Interaction between Human Bilateral Symmetrical Parts-Ou MC Decrescendo Phenomenon. Natural Science, 7, 71-80. http://dx.doi.org/10.4236/ns.2015.72008
} 
regulations with apoptosis, metastasis suppression, preventing uninhibited proliferation, minimizing angiogenesis and supervision by host immunological systems. These findings warrant further investigation.

\author{
Keywords \\ Cancer Regression, Ou MC Decrescendo Phenomenon, Normalization of Tissue Function, \\ Microenvironment, Apoptosis
}

\title{
1. Introduction
}

Our knowledge of cancer biology has led to many frontiers of cancer prevention, early detection, and treatment; nonetheless, modern cancer treatment is yet inefficient in comparison to other specific managements for example, antibiotics for infectious diseases [1] [2]. If cancer metastasis occurs, conventional cancer treatments as surgery, chemotherapy, and radiation therapy are generally incompetent and may eventually lead to patient death with severe complications. Recently-developed targeted treatments such as growth-signal inhibition, angiogenesis inhibition, and apoptosis induction pose fewer complications than conventional cancer treatments. Nonetheless, targeted cancer treatments may fail for targeted therapeutic agents usually inhibit key pathways in a tumor but can not completely cease malignant behavior of tumors or the resistance to targeted therapeutic agents may develop with tumor cells [2] [3]. Hormonal or biological response modifiers treatments also cause fewer side effects but also usually become ineffective if cancer resistance evolves [4] [5]. More frontiers against cancer are indicated to improve the capacity for cancer treatment.

The formation of a clinically-relevant tumor requires support from the surrounding stroma which also is referred to as the tumor microenvironment. Recent studies show that bidirectional interaction between tumor cells and microenvironment is essential for oncogenesis, tumor growth, and metastasis. Thus, many cellular and molecular elements of the tumor microenvironment are emerging as attractive targets for therapeutic strategies [6]. The way to normalize tumor microenvironment may be helpful to suppress tumor growth or extirpate cancer cells.

Ou MC decrescendo phenomenon (OuDP) is induced by the interaction between human bilateral symmetrical features [7] [8]. It has shown to be capable of normalizing tissue function, which has caused resolution of joint pain, soft tissue edema, constipation and organ dysfunction in recent studies. OuDP has also shown to be effective for patients with warts through long-term treatment [9] [10]. In this study, we further observe the effect of OuDP on cancer.

\section{Methods}

\subsection{Subjects}

From 2011 to 2014, four female patients separately with uterine endometrioid carcinoma, pancreatic isodense lesion, uterine leiomyosarcoma, and chronic myelogenous leukemia (CML) with gluteal macular cutaneous lesion performed self-administered HR (Table 1). The case with uterine leiomyosarcoma was treated with oral ergonovine maleate (Johnson Chemical, New Taipei City, Taiwan) and tranexamic acid (Standard Chem \& Pharm, Tainan, Taiwan) for the initial 5 days of the 3 weeks HR treatment while the patient with CML was treated with Glivec (Novaris, East Hanover, NJ, USA). These 2 cases were reported in a previous study and were included for an in-depth observation of OuDP's effect on human cancer [9]. The other 2 patients have not received other treatments.

\subsection{Ou MC Decrescendo Phenomenon Technique}

Ou MC handing remedy (HR) was performed to induce OuDP. The performance of HR is shown in Figure 1 and Table 2. The patient or therapist places the contralateral hand directly on the affected area (Figure 1). No further hand movement is required. For lesions on or adjoining the midline of the body, the HR is applied to one side of the lesion then to the other (Figure 1(B1-B3)). The amount of pressure is commensurate with the depth of the lesion (Figure 1(C1-C3)). Multiple fingers or the back of hand can be used if the palm cannot reach 
Table 1. The effect of Ou MC decrescendo phenomenon ${ }^{\mathrm{a}}$.

\begin{tabular}{|c|c|c|c|c|c|c|c|}
\hline \multirow{2}{*}{ Case } & \multirow{2}{*}{ Disease } & \multirow{2}{*}{ Age } & \multirow{2}{*}{ Diagnosis } & \multicolumn{2}{|c|}{ Ou MC handing remedy (HR) } & \multirow{2}{*}{ Short term effect } & \multirow{2}{*}{ Long term effect } \\
\hline & & & & Duration & Method & & \\
\hline 1 & $\begin{array}{c}\text { Uterine } \\
\text { endometrioid } \\
\text { cancer, } \\
\text { stage IIIB }\end{array}$ & 49 & Pathology & $\begin{array}{c}5 \\
\text { months }\end{array}$ & $\begin{array}{l}\text { Press hand on bilateral lower } \\
\text { abdomen and perineum in } \\
\text { first } 2 \text { months; then, press } \\
\text { hand deeply into bilateral } \\
\text { pelvis and press hand on } \\
\text { bilateral perineum and } \\
\text { whole abdomen occasional- } \\
\text { ly. }\end{array}$ & $\begin{array}{l}\text { Heavy uterine } \\
\text { bleeding diminishing } \\
\text { to trace and never } \\
\text { recurred up to date. }\end{array}$ & $\begin{array}{l}\text { a. Slow tumor regression } \\
\text { for first } 2 \text { months. } \\
\text { b. Stage IIIB regressing } \\
\text { to stage IA } \\
\text { in the next } 3 \text { months. }\end{array}$ \\
\hline 2 & $\begin{array}{l}\text { Suspicious } \\
\text { pancreatic } \\
\text { cancer IA } \\
\text { with isodense } \\
\text { lesion in } \\
\text { pancreatic tail }\end{array}$ & 51 & Radiology & $\begin{array}{c}4 \\
\text { months }\end{array}$ & $\begin{array}{c}\text { Press hand deeply into } \\
\text { epigastric area bilaterally } \\
\text { and occasionally on bilateral } \\
\text { costovertebral angles and } \\
\text { whole abdomen. }\end{array}$ & Not observed. & $\begin{array}{l}\text { a. Lesion size decreasing } \\
\text { from } 1.6 \times 1.7 \text { to } \\
1.0 \times 1.0 \mathrm{~cm} \text {. } \\
\text { b. Main pancreatic duct } \\
\text { diameter decreasing } \\
\text { from } 0.39 \mathrm{~cm} \text { to } 0.14 \mathrm{~cm} \text {. } \\
\text { c. CA } 199 \text { descending } \\
\text { from } 1090 \text { to } 136.5 \\
\text { (Unit } / \mathrm{ml}) . \text { CA } 125 \mathrm{from} \\
50.2 \text { to } 25.4 \text { (Unit } / \mathrm{ml}) \text {. }\end{array}$ \\
\hline 3 & $\begin{array}{l}\text { Uterine } \\
\text { leiomyosarcoma, } \\
\text { stage IB }\end{array}$ & 59 & Pathology & 3 weeks & $\begin{array}{l}\text { Press hand on } \\
\text { bilateral lower abdomen. }\end{array}$ & $\begin{array}{l}\text { Stopping active } \\
\text { uterine bleeding } \\
\text { immediately. }\end{array}$ & $\begin{array}{l}\text { Trace uterine bleeding } \\
\text { with following HR. }\end{array}$ \\
\hline 4 & $\begin{array}{l}\text { Perineal macular } \\
\text { lesion with CML }\end{array}$ & 39 & Inspection & 2 weeks & $\begin{array}{l}\text { Place finger directly } \\
\text { on the lesion. }\end{array}$ & Not observed. & Lesion resolved. \\
\hline
\end{tabular}

${ }^{\mathrm{a} O u}$ decrescendo phenomenon is induced by Ou MC handing remedy; CML, chronic myelogenous leukemia.

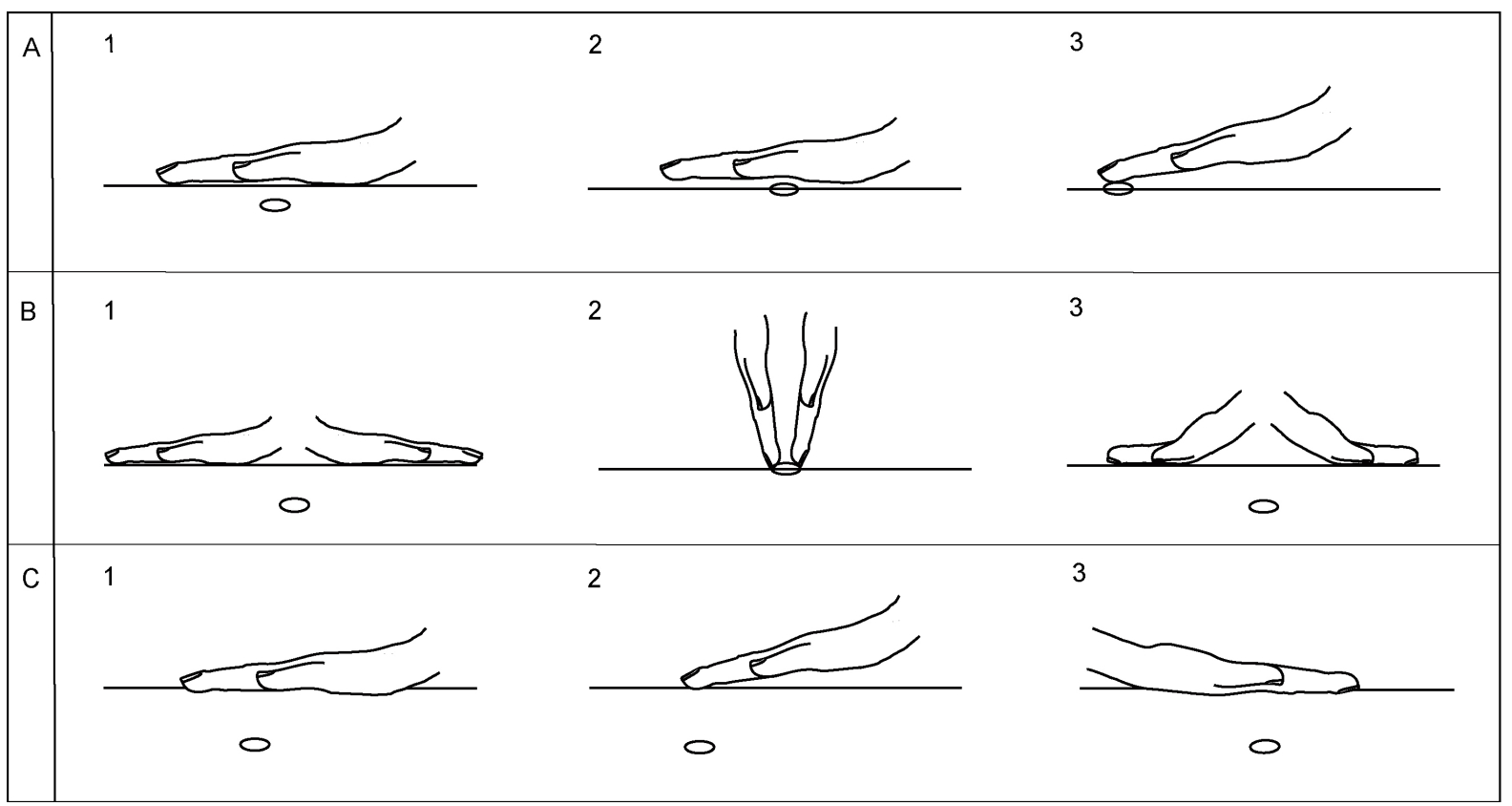

Figure 1. Schematic of the Ou MC handing remedy (HR) technique. The HR was performed by placing the contralateral hand on the affected area (A1-A3). For lesions on or adjoining the midline of the body, the HR is applied to one side of the lesion then to the other (B1-B3). The amount of pressure is commensurate with the depth of the lesion (C1-C3). Multiple fingers or the back of hand can be used if the palm cannot reach the affected area (A3-C3). For skin lesions, the palm may be kept about $0.5 \mathrm{~cm}$ over the lesion without touching the skin (A2). $\bigcirc=$ lesion. (From Ou MC et al. 2014; Ref. [9] [10]). 
the affected area (Figure 1(A3), Figure 1(B3), and Figure 1(C3)). For skin lesions, the palm may be kept approximately $0.5 \mathrm{~cm}$ above the lesion without touching the skin (Figure 1(A2)), which is detailed in Table 2 [9] [10]. All the patients were trained to administer HR by themselves.

\subsection{Informed Consent}

Though complementary therapy is exempt from informed consent by the law in Taiwan [11], all patients provided consent for participation in this study.

\section{Results}

\subsection{Uterine Endometrioid Carcinoma Stage IIIB}

\subsubsection{Disease}

This 49-year-old woman had recurrent menorrhagia and metrorrhagia for 5 years before HR treatment which has been performed from May 16, 2014 and this patient was followed up to November 4, 2014. On the night of May 15, 2014, she had profuse vaginal bleeding and received uterine dilatation and curettage (D \& C). During D \& C, a brownish tumor mass about $3 \mathrm{~cm}$ protruded from the cervical os and could not be removed by curettage. Biopsies of the cervical tumor and curettage of uterine cavity were performed. Pathology of both cervical biopsies and endometrium observed with an Olympus light microscopy (BX-51, Olympus, Tokyo, Japan) showed grade 1 endometrioid carcinoma (Figure 3(B1)) with negative for P16 (CINtec ${ }^{\circledR}$ Histology Kit, Ventana Medical Systems, Tuscon, AZ, USA), positive for vimentin (monoclonal mouse anti-vimentin, clone V9, DAKO, Glostrup, Denmark), estrogen receptor (estrogen receptor liquid mouse monoclonal antibody, NCL-L-ER-6F11, Newcastle, United Kingdom) and progesterone receptor (monoclonal mouse anti-human progesterone receptor, clone PgR 636, DAKO, Glostrup, Denmark). No definite squamous metaplasia or apoptosis-like lesion can be identified. Tumor markers as AFP, CEA, CA125, CA153, CA 199, and ferritin (Electro-chemiluminescence immunoassay, Elecsys, Roche Diagnostics GmbH, Mannheim, Germany), showed normal values.

\subsubsection{HR Treatment}

The patient refused medical or surgical treatment for unknown reason and began to perform HR since the next morning after D \& C by pressing her hands on the lower abdomen and perineal area for 1 - 2 minutes, 2 times a day (Figure 1(C1), Figure 1(C2)). Immediately, the vaginal bleeding rapidly decreased to a minimum with occasional spotting up to date. Computed tomography scan (CT) on May 18 showed a uterine tumor with suspicious myometrial penetration through the posterior wall of uterus (Figure 2(A1), Figure 2(A2)). Sonography on May 22 showed intrauterine mass about $8.5 \mathrm{~cm}$ in long axis and $4.1 \mathrm{~cm}$ in thickness with cervical involvement (Figure 3(A1)). The cervical protruding tumor shrank to approximately $1 \mathrm{~cm}$ in diameter on May 29 and disappeared on June 12. Another endometrial biopsy was performed on June 12 and showed tumor cells with prominent squamous metaplasia and apoptosis-like changes (Figure 3(B2), Figure 3(B3)). Sonography on June 12 showed the tumor continuously regressing (Figure 3(A2)). Nonetheless, MRI (Magnetic resonance imaging) on July 14 showed the size of intrauterine lesion about $8.7 \times 4.9 \times 3.2 \mathrm{~cm}$ (long axis $\times$ transverse $\times$ thickness) with parametrial invasion and penetrating through posterior uterine wall with rectal involvement (Figure 2(B1), Figure 2(B2)). A uterine endometrioid carcinoma stage IIIB (T3N0M1) was diagnosed for this patient.

\section{Table 2. Practical points for the application of self-administered Ou MC handing remedy (HR).}

1. The HR is performed by the patients themselves by placing the contralateral hand directly on the affected area according to Ou MC decrescendo phenomenon (Figure 1).

2. For lesions on or adjoining the midline of the body, the HR is applied first to one side of the lesion and then the other.

3. The effects of Ou MC decrescendo phenomenon are related to the duration, frequency of administration and the distance between the hand and the lesion.

4. If HR is not efficacious, measures such as getting the hand nearer to the lesion, applying other hand gesture and increasing the duration or frequency of administration may be helpful ${ }^{\mathrm{a}}$.

5. Patient positioning may be useful when performing the HR. For example, when treating lumbosacral pain, the patient may wish to lie down (supine) with the contralateral hand beneath the affected lumbosacral and adjoining areas.

6. Severe emotional disturbance possibly may affect HR's effectiveness ${ }^{\mathrm{b}}$.

${ }^{\mathrm{a}}$ The effect or appropriate duration and frequency of HR treatment for various diseases requires further study. ${ }^{\mathrm{b}} \mathrm{Whether}$ emotional disturbance affects the efficacy of the Ou MC decrescendo phenomenon is not explored in the present study (From Ou MC et al., 2014; Ref. [9] [10]). 


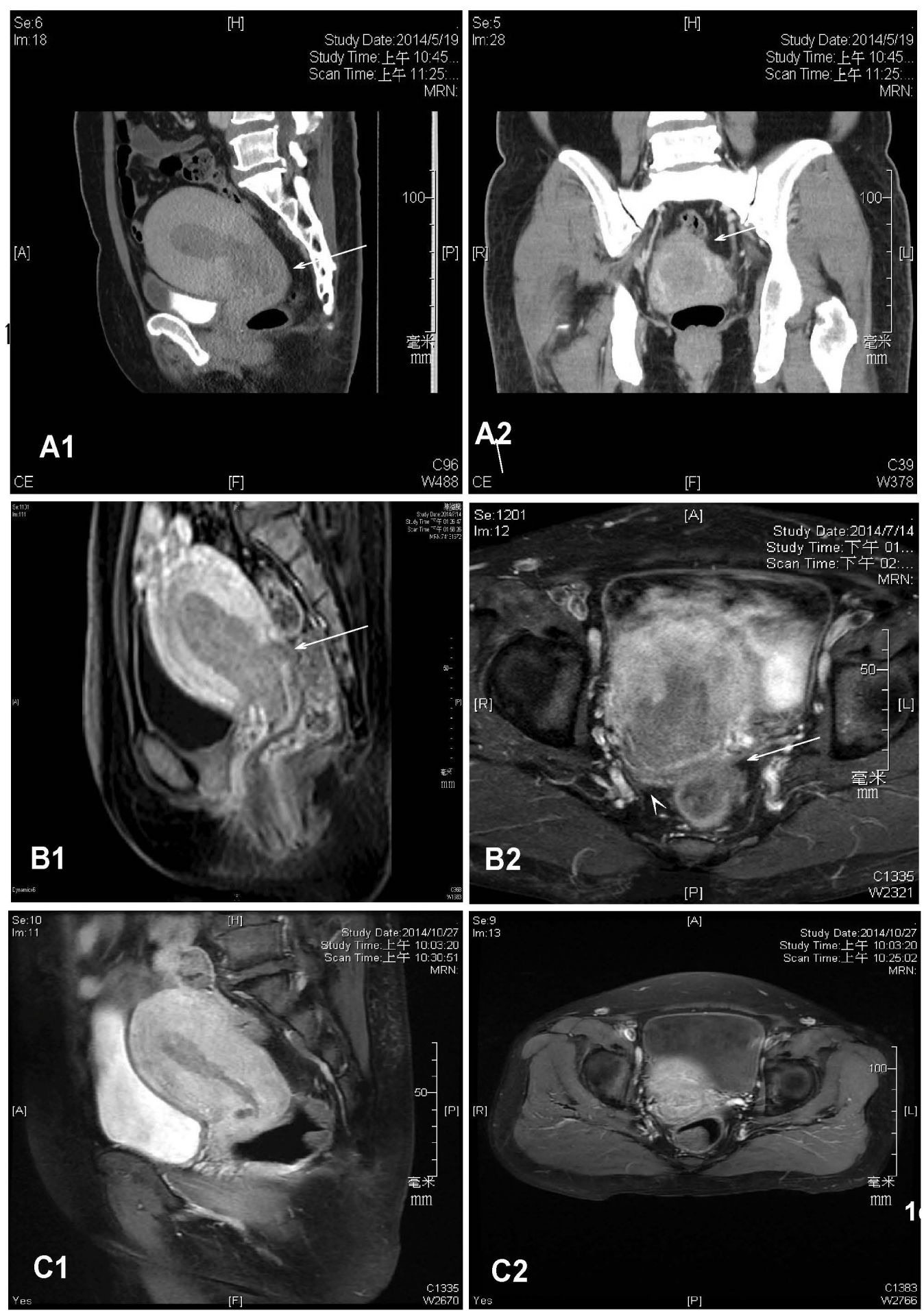

Figure 2. Uterine endometrioid carcinoma of case 1. (A) CT scan image on May 19, 2014. A1: the tumor involved uterine cavity and cervix with suspicious posterior uterine wall invasion (arrow). A2: the tumor with suspicious involvement of whole layer of posterior uterine wall (arrow). (B) MRI on July 14, 2014. B1: the lesion in uterine cavity about $8.9 \times 4.9 \times 4.5 \mathrm{~cm}$ (long axis $\times$ transverse $\times$ thickness) with posterior uterine wall invasion into the pelvis (arrow). B2: uterine parametrial invasion (arrow head) and posterior wall involvement with loss of the fat layer between uterine cervix and rectum (arrow). (C) MRI on October 27, 2014. C1: no posterior wall involvement and the lesion confined in uterine cavity about $6.7 \times 3.2 \times 1.5$ $\mathrm{cm}$. C2: uterine cervix with no tumor. CT scan, Computed tomography; MRI, Magnetic resonance imaging. 

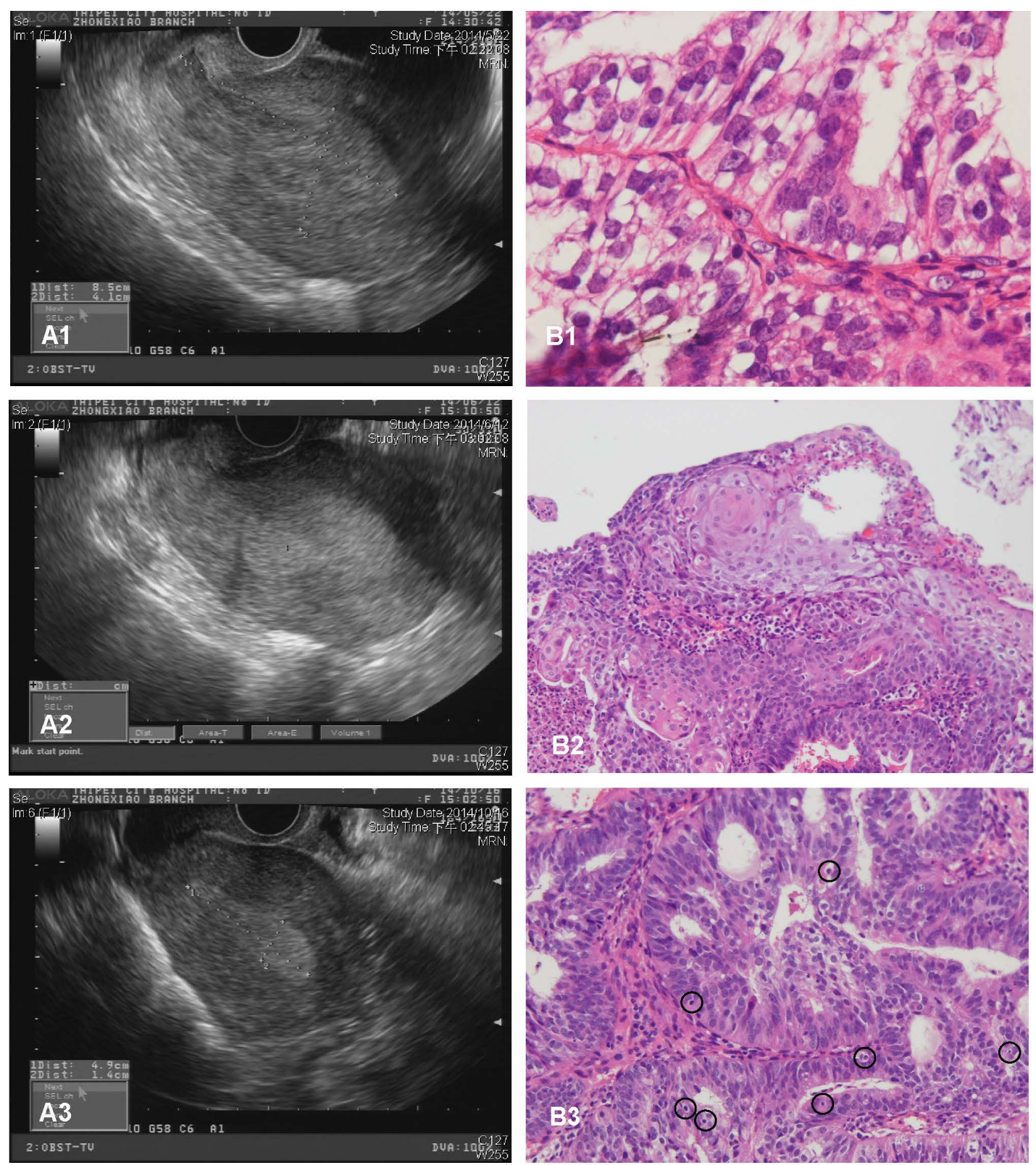

Figure 3. Uterine endometrioid carcinoma of case 1. (A) Sonography in 2014 on May 22 (A1), June 12 (A2) and October 16 (A3) showed continuous size reduction of the tumor. (B) Endometrial biopsy (hematoxylin and eosin staining, 3008-3, 3204-3, Muto Pure Chemical, Tokyo, Japan). (B1) Biopsy on May 15, 2014 showed well differentiated endometrioid carcinoma with secretory vacuoles. (magnification 400×). (B2) Biopsy on June 12, 2014 showed prominent squamous metaplasia of tumor cells (magnification 100×). (B3) Biopsy on June 12, 2014 showed numerous apoptosis-like cells (black circle, magnification 100×).

\subsubsection{Reinforced HR Treatment}

Thus, the patient began to reinforce HR treatment by placing her hand deeply into the bilateral pelvic region for 2 minutes on each side of uterus in the morning and 10 minutes at night (Figure 1(C1), Figure 1(C2)). She also placed her hand on the contralateral perineal area or other abdominal areas if experiencing abdominal fullness (Figure 1(C1), Figure 1(C2)). Sonography on October 16 showed an intrauterine mass about $4.9 \times 1.8 \times 1.4 \mathrm{~cm}$ with no cervical involvement (Figure 3(A3)). MRI on October 27 showed intrauterine mass about $6.7 \times 3.2 \times$ 1.5 with no cervical, parametrial or pelvic involvement (T1N0M0, Stage IA, Figure 2(C1), Figure 2(C2)); however, this patient refused endometrial biopsy on November 4. 


\subsection{Suspicious Pancreatic Cancer IA with Elevated CA199 and Dilated Tortuous Main Pancreatic Duct}

\subsubsection{Disease}

This 51-year-old patient was discovered with CA-199 of 67.1 (Unit/ml) (normal <27) and CA125 of 31 (Unit/ml) (normal <35) on March 13, 2014. She was followed up to October 21, 2014. CA 199 of 1090.0 and CA125 of 46.5 were found for her on May 26. The CT scan examination she received on May 29 showed an isodense nodule about $1.6 \times 1.7 \mathrm{~cm}$ in greatest dimension (Figure 4(A1), Figure 4(A2)) in the pancreatic tail with dilated tortuous main pancreatic duct in a diameter about $0.39 \mathrm{~cm}$ (Figure 4(A3)). A pancreatic cancer, stage IA was tentatively presumed.
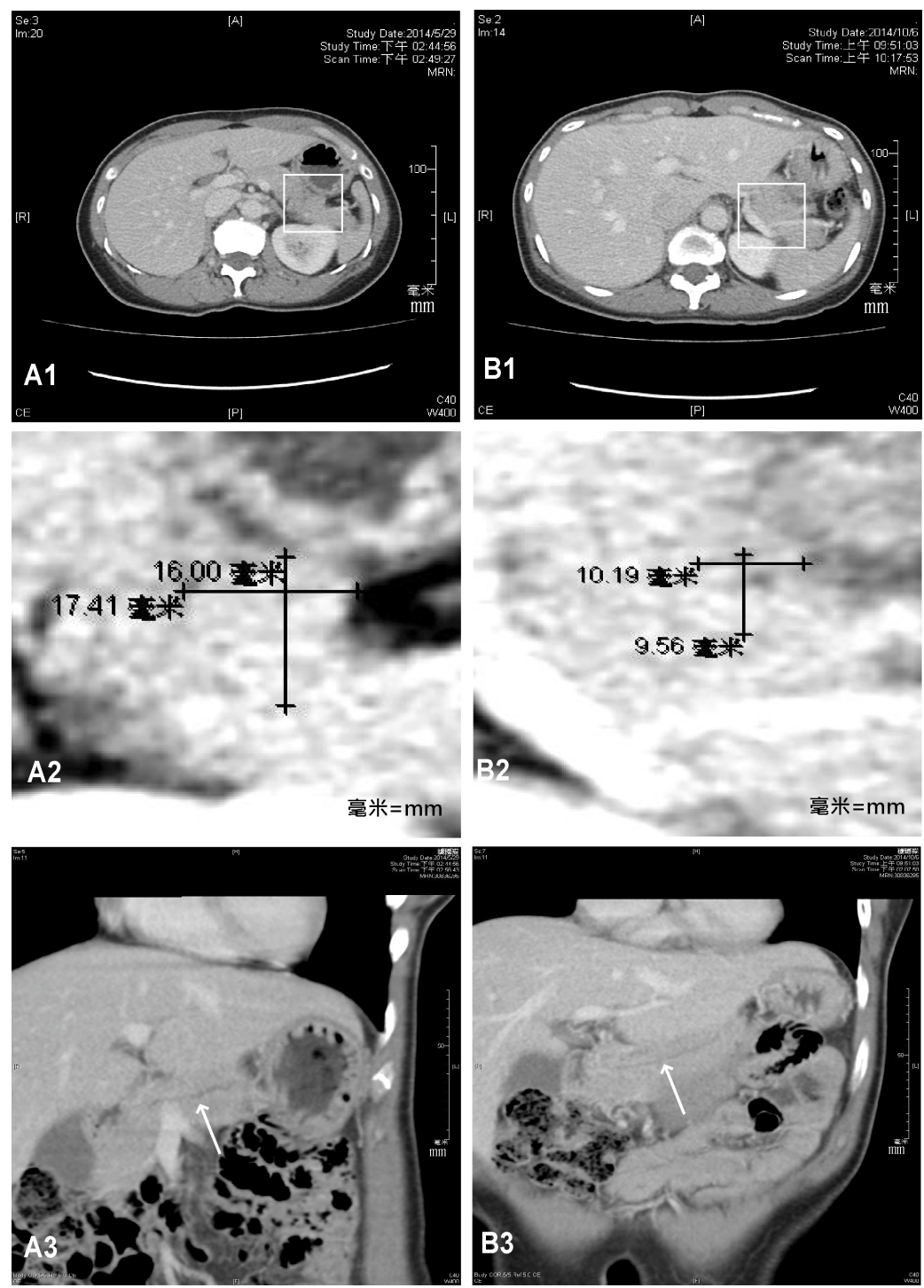

Figure 4. CT scan for suspicious pancreatic cancer IA of case 2. (A) CT scan on May 29, 2014. (A1) An isodense nodule in pancreatic tail (square area). (A2) Magnified photo of the square area of A1, showed the size of the isodense nodule about $1.6 \times 1.7 \mathrm{~cm}$. (A3) Dilated tortuous main pancreatic duct of the pancreas with diameter about $0.39 \mathrm{~cm}$ (arrow). (B) CT scan on October 6, 2014. (B1) The isodense nodule in pancreatic tail in the same position of the square area of A1. (B2) Magnified photo of the square area of B1 showed the size of the isodense nodule about $1.0 \times 1.0 \mathrm{~cm}$. (B3) Main pancreatic duct of pancreas with smooth feature about $0.14 \mathrm{~cm}$ in diameter (arrow). CT scan, computed tomography scan. 


\subsubsection{HR Treatment}

The patient refused surgical approach for the possibly poor prognosis of this disease and received HR management from June 5. She performed HR with her hands applied heavily onto the bilateral epigastric area for 5 minutes on each side 2 times a day (Figure 1(C1), Figure 1(C2)) and occasionally on bilateral costovertebral angles (Figure 1(B3), Figure 1(C3)) and other abdominal areas (Figure 1(C1), Figure 1(C2)). CA199 and CA125 which were recorded as 1090.0 and 46.5 before the initiation of HR separately became 170.5 and 50.2 on June 11 and 136.5 and 25.4 on October 3. CT scan on October 6 indicated that the isodense nodule shrank to approximately $1.0 \times 1.0 \mathrm{~cm}$ in the greatest dimension (rounded from $10.19 \times 9.56 \mathrm{~mm}$, Figure 4(B1), Figure 4(B2)). Also, the main pancreatic duct became smooth in feature with the diameter decreasing to approximately $0.14 \mathrm{~cm}$ (Figure 4(B3)). There was no abdominal or back discomfort during this study or history of pancreatitis for this patient.

\subsection{Uterine Leiomyosarcoma IB}

\subsubsection{Disease}

This 59-year-old patient suffered from heavy uterine bleeding ( 7 to 8 fully-soaked pads/day) for 2 months before receiving uterine D \& C which was performed on July 31, 2013 and showed atypical muscle tumor. Her uterine bleeding was profuse when she visited our clinic on August 8, 2013.

\subsubsection{HR Treatment}

Vaginal speculum observations showed that the heavy uterine bleeding immediately decreased to a minimum with a 1-minute HR treatment on each side of the lower abdomen. In a supine position, she then applied HR by press hand over the lower abdomen on each side of the uterus for about 2 - 3 minutes for 3 - 4 times daily (Figure 1(C1)). The HR was found to be effective at minimizing heavy uterine bleeding. CT scan on August 15, 2013 showed a heterogeneous lesion about $11.0 \times 13.2 \mathrm{~cm}$ in uterus. Hysterectomy and bilateral adnexectomy on August 29, 2013 showed 2 myoma-like tumors about $11.5 \times 6.6 \times 6.5$ and $8.1 \times 8 \times 4.5 \mathrm{~cm}$ limited in the uterine body with ill-defined margins. Pathology of both tumors observed with an Olympus light microscope (DP20, Olympus, Tokyo, Japan) showed leiomyosarcoma with no lymph node or other pelvic organ involved (Stage IB, T1N0M0).

\subsection{Perineal Brownish Macular Lesion with Chronic Myelogenous Leukemia}

\subsubsection{Disease}

This 39-year-old patient had CML and underwent remission for 1 year via Glivec treatment. Upon admittance to our clinic, we discovered on her left gluteal area, a painless brownish macular lesion about $3.5 \times 4.2 \mathrm{~cm}$ in dimension and $0.3 \mathrm{~cm}$ in thickness which did not respond to antibiotic treatment.

\subsubsection{HR Treatment}

This patient performed HR for 2 minutes on the perineal lesion (Figure 1(A3)) twice daily. With solely HR, the perineal lesion became smaller and resolved 2 weeks later. However, this patient refused a biopsy of the macular lesion.

\section{Discussion}

Cancer is considered a genetic disease as most cancers have been associated with gene-related changes caused by physical, chemical, infectious, or hereditary factors that impair or activate the gene relating to the occurrence of cancer. Oncogene activation or impaired cancer suppression genes are related to genesis, proliferation or metastasis of cancer cells but researches have shown that most oncogene activation or impaired cancer suppression genes do not cause cancer since the initiated cells usually became apoptotic or killed by host defense systems prior to the promotion to cancer. Studies also show that further proliferation-enhancing signals are required to progress along the pathway towards cancerous growth. Cancer requires multiple steps to manifest. Such steps involve poor immunological response, defective genetic repairing, dysregulated and modified epigenetic presentation, loss of intracellular surveillance for cell death, and alternated intercellular micro-environmental interactions [3]. With understanding these in tumor biology, the medications which target specific biological path- 
ways of cancer have been developed and become a corner stone for cancer treatment in this century. However, the plasticity of cancer cells allows for development of selective resistance against target-specific therapeutic agents. Modern treatments for cancer yet remain largely incompetent toward most cancers, especially if cancer metastasis occurs [2].

OuDP appears to be consistently effective for treating a wide variety of diseases in terms of distance between hand and lesion, treatment duration and performance frequency. The effect of OuDP can be significantly increased by decreasing the distance between hand and lesion, increasing treatment duration, and raising treatment frequency. Prompt remission of joint pain, edema of soft tissue by trauma, pain by infection or cessation of uterine bleeding in the studies with OuDP indicate a restoration of normal tissue function [9]. Restoration of normal tissue function may re-establish host defense systems, which will contribute to defense against microorganisms, inflammation, degenerative changes, and tumors [9] [10]. The normalization of function of tumor cells may make them conform to the regulations by apoptosis, growth suppression, and metastatic hindrance that undergo with normal cells. The normalization of tissue function by OuDP apparently not only involves the tumor cell but also the microenvironment in which tumor cells lodge. The tumor microenvironment has been regarded as a main factor for tumor development and metastasis. A normalization of tumor microenvironment will place tumor cells under the circumstances that suppress metastasis, prevent uninhibited proliferation, minimize angiogenesis and eliminate abnormal cells with normalized host immunological systems [6] [12].

A past study of the snapping shrimp has shown that interactions between individual shrimps and other shrimps (with different claw shapes and fiber composition) will induce the change of shape and fiber composition of both claws of the individual shrimp [13]. Our previous study also showed that interactions between patient and HR therapist presented similar results via self-administered HR. There is no significant difference between self- and therapist-performed HR to induce OuDP, but the effect of HR is related to application duration, frequency, and distance. Self-administered HR may increase the efficacy of cancer treatment with increasing the frequency and duration of application by patients themselves. However, this study shows the effect of OuDP for treating oncologic diseases depends on distance between hand and lesion. Thus, the OuDP effect may not be well induced for lesions that cannot be fully accessed.

In 1999, it was noted that cancer patients did not fare better than patients treated decades ago [1]. Since 2000, with recent growing understanding of cancer cell biology, modern medicine has approached various alternative ways as a back-up for conventional cancer treatments. The 5-year relative survival rate for all cancers diagnosed between 2003 and 2009 is 68\%, up from 49\% in 1975-1977 in USA [2]; however, the morbidity and mortality by cancer is yet much higher than those for most of other diseases. Cancer treatment itself may often impact patients' quality of life due to side effects or complications. An ideal treatment should be effective to ameliorate disease but causes minimal side effects or complications. A recent Swedish statistical study shows there it was discovered that the breast cancer of many patients spontaneously regressed without treatments [14]. It shows spontaneous cancer regression is not rare though the mechanism remains speculative. The OuDP effect shows the capacity to bring about tumor regression, which is comparable with the spontaneous cancer regression reported.

\section{Conclusion}

In summary, OuDP is induced by the interaction of human bilateral symmetrical features and has proven to accelerate the recovery processes for inflammation, degenerated diseases, tissue dysfunction, and oncological changes. The resolution of non-infectious conditions with OuDP is consistent with the restoration of normal tissue function. This restoration of normal tissue function for cancer indicates to involve not only tumor cells but also the tumor microenvironment, which may make tumor cells conform to the regulations for normal cells as with apoptosis, metastasis suppression, preventing uninhibited proliferation, minimizing angiogenesis and supervision with host immunological systems. However, due to the relatively small sample-size in our study, future studies are warranted to replicate these findings.

\section{Acknowledgements}

The authors thank Dr. Yi-Chin Chang (Taipei City Hospital) and Dr. Jan-Show Chu (Taipei Medical University Hospital) for providing pathological photos; thank Dr. Jen-Dar Chen (Taipei City Hospital) and Professor AnHang Yang (Yang-Ming University) for consultations on radiography and pathology; thank the department of 
pathology and laboratory (Taipei City Hospital) for providing the information about staining, immunochemistry and tumor marker analysis; and thank Ms. Yi-Jen Ou for the assistant work.

\section{Conflict of Interest}

The authors declare that they have no conflict of interest.

\section{References}

[1] Richardson, M.A., Ramirez, T., Russell, N.C. and Moye, L.A. (2014) Coley Toxins Immunotherapy: A Retrospective Review. Alternative Therapies, Health and Medicine, 5, $42-47$.

[2] The American Cancer Society (2014) Cancer Facts \& Figures 2014. http://www.cancer.org/acs/groups/content/@research/documents/webcontent/acspc-042151.pdf

[3] Hanahan, D. and Weinberg, R.A. (2011) Hallmarks of Cancer: The Next Generation. Cell, 144, 646-674. http://dx.doi.org/10.1016/j.cell.2011.02.013

[4] Musgrove, E.A. and Sutherland, R.L. (2009) Biological Determinants of Endocrine Resistance in Breast Cancer. Nature Reviews Cancer, 9, 631-643. http://dx.doi.org/10.1038/nrc2713

[5] Igney, F.H. and Krammer, P.H. (2002) Immune Escape of Tumors: Apoptosis Resistance and Tumor Counterattack. Journal of Leukocyte Biology, 71, 907-920.

[6] Lorusso, G. and Rüegg, C. (2008) The Tumor Microenvironment and Its Contribution to Tumor Evolution toward Metastasis. Histochemistry and Cell Biology, 130, 1091-1103. http://dx.doi.org/10.1007/s00418-008-0530-8

[7] Ou, M.C., Pang, C.C. and Ou, D. (2011) Abdominal Palpation with Ou MC Manipulation (APOM) for Women with Acute Abdomen Caused by Pelvic Inflammatory Disease: A Pilot Study. JEM, 41, 87-89.

[8] Ou, M.C., Pang, C.C., Ou, D. and Su, C.H. (2012) The Implications of Abdominal Palpation with Ou MC Manipulation for Women with Acute Abdomen. American Journal of Emergency Medicine, 30, 421-425. http://dx.doi.org/10.1016/j.ajem.2011.01.008

[9] Ou, M.C., Ou, D. and Pang, C.C. (2014) A Primitive Approach to Ou MC Decrescendo Phenomenon with a Hands-On Therapy-The Relation between Human Bilateral Symmetry and Disease. Natural Science, 2, 88-98. http://dx.doi.org/10.4236/ns.2014.62013

[10] Ou, M.C., Ou, D. and Pang, C.C. (2014) The Relation between Human Bilateral Symmetry and Disease. Proceedings of the Physiological Society, 31, PCA132. http://www.physoc.org/proceedings/abstract/Proc\%20Physiol\%20Soc\%2031PCA132

[11] Department of Health, Executive Yuan (1993) No.82075656. http://homepage.vghtpe.gov.tw/ ged/listn/listn_a122.htm

[12] Dunn, G.P., Koebel, C.M. and Schreiber, R.D. (2006) Interferons, Immunity and Cancer Immunoediting. Nature Reviews Immunology, 6, 836-848. http://dx.doi.org/10.1038/nri1961

[13] Pearce, J. and Govind, C.K. (1987) Spontaneous Generation of Bilateral Symmetry in the Paired Claws and Closer Muscles of Adult Snapping Shrimps. Development, 100, 57-63.

[14] Zahl, P.H., Gotzsche, P.C. and Mahlen, J. (2011) Natural History of Breast Cancers Detected in the Swedish Mammography Screening Programm: A Cohort Study. The Lancet Oncology, 12, 1118-1124. 
Scientific Research Publishing (SCIRP) is one of the largest Open Access journal publishers. It is currently publishing more than 200 open access, online, peer-reviewed journals covering a wide range of academic disciplines. SCIRP serves the worldwide academic communities and contributes to the progress and application of science with its publication.

Other selected journals from SCIRP are listed as below. Submit your manuscript to us via either submit@scirp.org or Online Submission Portal.
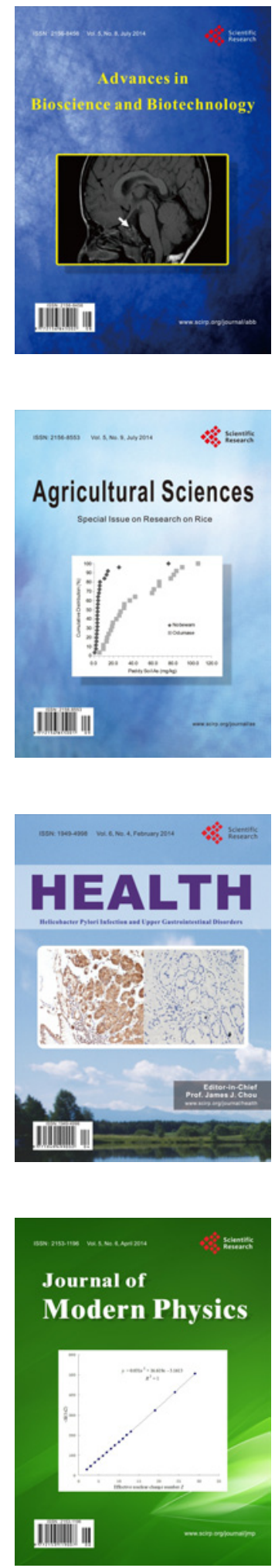
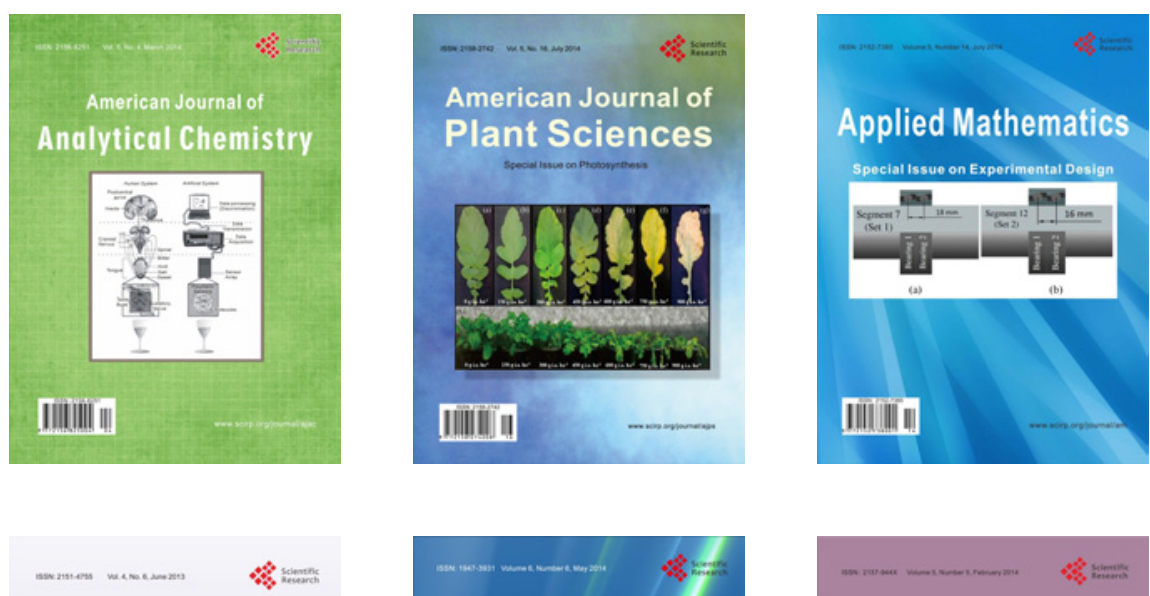

Creative Education
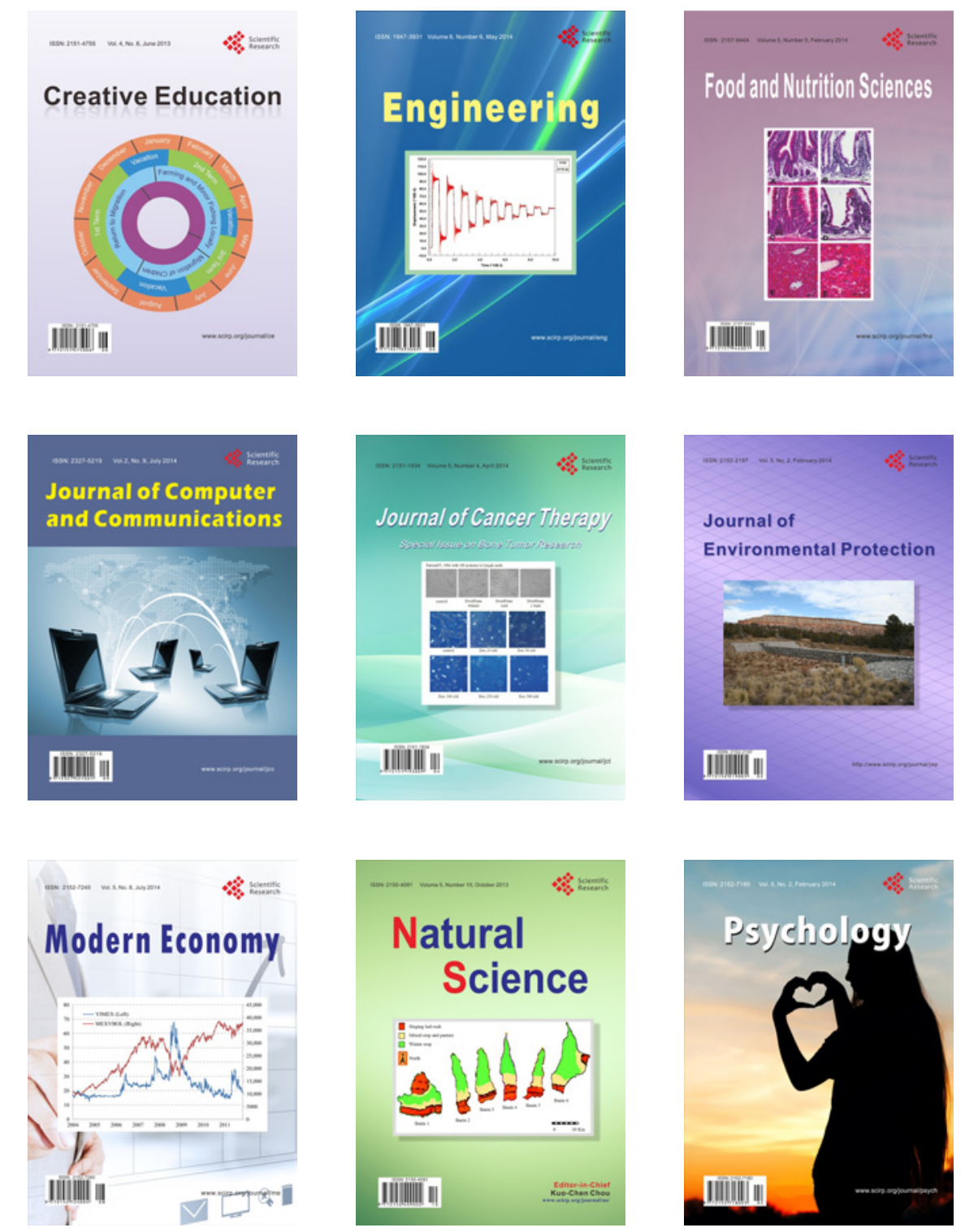